OPEN ACCESS

Edited by:

João Agostinho Machado-Neto, University of São Paulo, Brazil

Reviewed by:

Juan Luiz Coelho Da Silva, University of São Paulo, Brazil

Bryan E. Strauss,

University of São Paulo, Brazil

*Correspondence:

Chih-Ching Yen

d5210@mail.cmuh.org.tw

Chuan-Mu Chen

chchen1@dragon.nchu.edu.tw

Specialty section:

This article was submitted to Molecular and Cellular Oncology,

a section of the journal

Frontiers in Cell and Developmental

Biology

Received: 30 March 2021

Accepted: 31 May 2021

Published: 21 June 2021

Citation:

Wang J-L, Lan Y-W, Tsai Y-T, Chen $Y$-C, Staniczek T, Tsou Y-A Yen $C-C$ and Chen C-M (2021)

Additive Antiproliferative

and Antiangiogenic Effects

of Metformin and Pemetrexed in a

Non-Small-Cell Lung Cancer

Xenograft Model.

Front. Cell Dev. Biol. 9:688062. doi: 10.3389/fcell.2021.688062

\section{Additive Antiproliferative and Antiangiogenic Effects of Metformin and Pemetrexed in a Non-Small-Cell Lung Cancer Xenograft Model}

\author{
Jiun-Long Wang 1,2, Ying-Wei Lan', Yi-Ting Tsai ${ }^{3}$, Ying-Cheng Chen', Theresa Staniczek4, \\ Yung-An Tsou ${ }^{5}$, Chih-Ching Yen ${ }^{6 *}$ and Chuan-Mu Chen ${ }^{1,7 *}$ \\ 1 Ph.D. Program in Translational Medicine, Department of Life Sciences, National Chung Hsing University, Taichung, Taiwan, \\ ${ }^{2}$ Division of Chest Medicine, Department of Internal Medicine, Taichung Veterans General Hospital, Taichung, Taiwan, \\ ${ }^{3}$ Division of Endocrinology and Metabolism, Department of Internal Medicine, Taichung Veterans General Hospital, Taichung, \\ Taiwan, ${ }^{4}$ Department of Dermatology, Venereology and Allergology, Center of Excellence in Dermatology, University Medical \\ Center and Medical Faculty Mannheim, Heidelberg University, Mannheim, Germany, ${ }^{5}$ Department of Otolaryngology-Head \\ and Neck Surgery, China Medical University Hospital, Taichung, Taiwan, ${ }^{6}$ Department of Internal Medicine, China Medical \\ University Hospital, College of Health Care, China Medical University, Taichung, Taiwan, ${ }^{7}$ The iEGG and Animal \\ Biotechnology Center, Rong Hsing Research Center for Translational Medicine, National Chung Hsing University, Taichung, \\ Taiwan
}

Lung cancer is heterogeneous and challenging to cope with once it has progressed. Chemotherapy is the first step once no active driver mutation has been discovered. Non-antitumor drugs have been found to be beneficial when used as adjuvants to chemotherapy. In this study, the additive effect and mechanism of metformin combined with pemetrexed in non-small-cell lung cancer (NSCLC) cells were elucidated. Three NSCLC cell lines, A549, H1975, and HCC827, were used to analyze tumor cell proliferation, colony formation and the cell cycle in vitro when exposed to metformin alone, pemetrexed alone or their combination. We found that combination treatment in three cell lines exerted antiproliferative effects through cell cycle arrest in the $S$ phase. An ex vivo chicken chorioallantoic membrane (CAM) assay was used to examine the antiangiogenic effect of metformin combined with pemetrexed on vascular structure formation. We further created an A549 orthotopic xenograft model with an in vivo imaging system (IVIS) and explored the associated indicators involved in the tumorigenic process. The in vitro results showed that the combination of metformin and pemetrexed exhibited an antiproliferative effect in reducing cell viability and colony formation, the downregulation of cyclin D1 and $\mathrm{A} 2$ and the upregulation of CDKN1B, which are involved in the G1/S phase. For antiangiogenic effects, the combination therapy inhibited the vascular structure, as proven by the CAM assay. We elucidated that combination therapy could target VEGFA and Endoglin by RT-qPCR, ELISA and histopathological findings in an A549 orthotopic NSCLC xenograft model. Our research demonstrated the additive antiproliferative and antiangiogenic effects of the combination of metformin with pemetrexed in NSCLC and could be applied to clinical lung cancer therapy.

Keywords: metformin, pemetrexed, lung cancer, angiogenesis, orthotopic xenograft, chorioallantoic membrane 


\section{INTRODUCTION}

Lung cancer remains a challenging obstacle and ranks as the leading cause of mortality worldwide, including in Taiwan (Hsu et al., 2015; Siegel et al., 2017; Tseng et al., 2019). The most common type of lung cancer is non-small-cell lung cancer (NSCLC), which accounts for up to $85 \%$ of all cases. Lung adenocarcinoma is predominant among NSCLC, and most patients are diagnosed with an advanced or metastatic status (Levy and Doyen, 2018). Once driver mutations, such as those in epidermal growth factor receptor (EGFR) or echinoderm microtubule-associated protein-like 4-anaplastic lymphoma kinase (EML4-ALK) fusion mutations, are detected, targeted therapy can be applied (Hsu et al., 2015; Mok et al., 2017; Soria et al., 2017). Discovery of the expression of programmed death-1 (PD-1) or PD-ligand 1 (PD-L1) makes the patient a candidate for the use of immune checkpoint inhibitors (ICIs) (Reck et al., 2016, 2019; Berghmans et al., 2020; Satouchi et al., 2020). When patients do not harbor active driver mutations or immune checkpoint expression, chemotherapy is the mainstream treatment.

Among chemotherapeutic agents, pemetrexed (Alimta ${ }^{\circledR}$ ) is chosen for front-line therapy in advanced or metastatic NSCLC (especially for lung adenocarcinoma) in a single use for maintenance or combined with platinum for first line therapy (Scagliotti et al., 2008; Belani et al., 2012a,b). Pemetrexed is an antineoplastic agent and has an antifolate effect. A 3week therapy is arranged in clinical practice. Maintaining chemotherapy efficacy and overcoming drug resistance are essential. Because a great amount of time and money is required to develop new drugs (Saxena et al., 2015), repositioning or repurposing present non-antitumor drugs for potential antitumor effects has drawn much attention, and an increasing number of studies have been devoted to this idea.

Metformin was first used as an oral antidiabetic agent (OAD) and is widely used for sugar control. It inhibits gluconeogenesis and reduces insulin resistance, which is essential for tumor growth (Pawalowska and Markowska, 2012). Based on earlier observation studies, diabetic patients under metformin treatment were observed to have a lower cancer incidence, with an up to $23 \%$ reduction rate compared with other OAD groups (Evans et al., 2005; Currie et al., 2012) and an approximately 39 45\% reduction in the Taiwanese population (Lai et al., 2012). Recent observational studies showed that metformin use is beneficial for the lung cancer population (Lin et al., 2015; Arrieta et al., 2016; Chuang et al., 2018; Brancher et al., 2020; Kang et al., 2021). Dosage and time dependent effects have been extensively shown. In preclinical studies, metformin demonstrates additive effects when combined with antitumor reagents and can overcome drug resistance and reduce chemotherapeutic dosages (Kato et al., 2012; Lin et al., 2013; Tseng et al., 2013; Fatehi Hassanabad and MacQueen, 2020).

Metformin can activate adenosine monophosphate-activated protein kinase (AMPK) and negatively regulate the mammalian target of rapamycin (mTOR) pathway. The AMPK pathway is supported by liver kinase B1 (LKB1) (Zakikhani et al., 2006; Sinnett-Smith et al., 2013). The mTOR pathway is responsible for cell viability, protein synthesis and proliferation. Targeting the mTOR pathway halts cell proliferation and growth. When metformin is used alone or combined with chemotherapeutic agents, more theories have been proposed (Peng et al., 2017; Levy and Doyen, 2018; Fatehi Hassanabad and MacQueen, 2020). Luo et al. (2019) found that metformin induces apoptosis by promoting survivin degradation through the AMPK/PKA (protein kinase A)/GSK (glycogen synthase kinase)-3B pathway in NSCLC. Other research showed that the combination of metformin with cisplatin leads to decreased expression of vascular endothelial growth factor-C (VEGF-C) and VEGF receptor-3 (VEGFR-3) at the protein and mRNA levels (Chen and Chen, 2015).

Few studies have focused on the antitumor mechanism induced by metformin combined with pemetrexed. Although a lung cancer cell line in vitro study performed by Zhang et al. (2017) proposed antiproliferative and apoptosis processes, there is still a lack of in vivo studies and real-time imaging monitoring to expand and elucidate the possible mechanism besides the AMPK-dependent pathway. Therefore, we set up serial experiments and platforms in in vitro, ex vivo and in vivo models to identify potential additive and novel therapeutic targets, such as angiogenesis, in combination therapy with metformin and pemetrexed in non-small-cell lung cancer.

In this study, the combination therapy of metformin with pemetrexed was designed to test the additive effect of antiproliferation on three NSCLC cell lines through the study of cell viability, colony formation and cell cycle functions. The additive antiangiogenic effect was proven by a chicken chorioallantoic membrane (CAM) assay and an orthotopic NSCLC xenograft model. The expression of VEGF-associated angiogenic indicators (VEGF and Endoglin) and the tumor marker carcinoembryonic antigen (CEA) was also determined for a mechanistic study.

\section{MATERIALS AND METHODS}

\section{Chemicals}

Metformin hydrochloride and crystal violet were purchased from Sigma-Aldrich (St. Louis, MO, United States). Pemetrexed was obtained from Eli Lilly and Company (Indianapolis, IN, United States).

\section{Cell Lines}

Human lung adenocarcinoma cell lines A549 (ATCC CCL-185), H1975 (ATCC CRL-5098), and HCC827 (ATCC CRL-2868) were purchased from the American Type Culture Collection (Manassas, VA, United States), and an A549 stable dual fluorescent protein-expressing cell line (A549-iRFP-2A-Venus) was established previously (Lai et al., 2016). Normal human embryonic lung cell line WI-38 VA-13 subline 2RA (WI382RA; BCRC-60504) was purchased from Bioresource Collection and Research Center (Hsinchu, Taiwan). Both A549 cell lines were maintained in Ham's F12K medium (Life Technologies; Waltham, MA, United States); H1975 and HCC827 cell lines were 
maintained in RPMI1640 medium (Life Technologies); WI382RA cell line was maintained in Eagle's minimal essential medium (Life Technologies). All culture medium was supplemented with $10 \%$ fetal bovine serum (FBS; Life Technologies), $2 \mathrm{mM}$ L-glutamine (Life Technologies) and 1\% penicillin/streptomycin (Life Technologies), and were incubated at $37^{\circ} \mathrm{C}$ in a $5 \%$ $\mathrm{CO}_{2}$ incubator.

\section{Cell Viability MTT Assay}

A549, H1975, and HCC827 cells were seeded in 24-well culture plates ( $5 \times 10^{4}$ cells; BD Biosciences, La Jolla, CA, United States) and incubated overnight to allow adhesion. The cells were treated with metformin (Met; $0.2 \mathrm{mM}$ ), pemetrexed (Pem; $1 \mu \mathrm{M}$ ), or both $(0.2 \mathrm{mM}$ Met $+1 \mu \mathrm{M}$ Pem $)$ for $48 \mathrm{~h}$. The viable cells were stained and detected using the MTT [3-(4,5-dimethylthiazol2-yl)-2,5-diphenyltetrazolium bromide] staining method at a wavelength of $540 \mathrm{~nm}$ by a Multiskan GO spectrophotometer (Thermo Fisher Scientific; Waltham, MA, United States) as previously described (Lan et al., 2015).

\section{Cell Proliferation and Colony-Forming Unit Assay}

A549, H1975, and HCC827 cells were seeded at 1,000 cells/well in 12-well culture plates (BD Biosciences) and incubated overnight to allow adhesion. The cells were treated with metformin (Met; $0.2 \mathrm{mM}$ ), pemetrexed (Pem; $1 \mu \mathrm{M}$ ), or both (Met; $0.2 \mathrm{mM}+$ Pem; $1 \mu \mathrm{M})$, and the cultures had a replacement of fresh drug and culture medium every 2 days. After 10 days in culture, the cells were washed with DPBS, fixed with $10 \%$ formalin for $2 \mathrm{~min}$, and stained with $0.5 \%$ crystal violet (dissolved in methanol) for $20 \mathrm{~min}$ at room temperature. The crystal violet solution was removed, after which the cells were washed with DPBS at least twice to get a clear background. Representative photographs were captured using a camera, and the quantification of the crystal violet-positive staining was performed using NIH Image software (ImageJ 1.35 d; NIH, Bethesda, MD, United States).

\section{Cell Cycle Analysis}

A549, H1975, and HCC827 cells were treated with metformin $(0.2 \mathrm{mM})$ and/or pemetrexed $(1 \mu \mathrm{M})$ for $48 \mathrm{~h}$. The cells were harvested and stained as previously described (Hung et al., 2014). The cells were fixed with $70 \%$ ice-cold ethanol and incubated at $-20^{\circ} \mathrm{C}$ for $1 \mathrm{~h}$. The fixed cells were centrifuged and the pellets were resuspended in lysis buffer $(0.5 \%$ Triton X-100 and RNAse $\mathrm{A}$ at $10 \mu \mathrm{g} / \mathrm{ml}$ ) (Life Technologies) at $37^{\circ} \mathrm{C}$ for $40 \mathrm{~min}$. The cells were stained with $50 \mu \mathrm{g} / \mathrm{ml}$ propidium iodine (Sigma-Aldrich, St. Louis, MO, United States). After $20 \mathrm{~min}$ of incubation at $4^{\circ} \mathrm{C}$ in the dark, the stained cells were analyzed using an Accuri C6 Plus flow cytometer (BD Biosciences). The percentages of cells in the G1, S, and G2/M phases were calculated using Accuri C6 Plus software (BD Biosciences).

\section{FITC Annexin V Apoptosis Detection Assay}

A549, H1975, and HCC827 cells were treated with metformin $(0.2 \mathrm{mM})$ and/or pemetrexed $(1 \mu \mathrm{M})$ for $48 \mathrm{~h}$. The cells were harvested and stained according to the manufacturers' protocols (BD Biosciences). The cells were analyzed using Accuri C6 Plus flow cytometer (BD Biosciences). The percentage of apoptotic cell in each quadrant was calculated using Accuri C6 Plus software (BD Biosciences).

\section{Western Blot Analysis}

Western blot analysis was performed as previously described (Lan et al., 2019). The antibodies used were anti-phosphoAMPK (Thr172), anti-AMPK, anti-phosphoAkt (Ser473), anti-panAkt, anti-CDKN1B (Cell Signaling Technology, Danvers, MA, United States), anti-cyclin D1 (Abcam, Cambridge, MA, United States), and anti- $\beta$-actin (Novus Biologicals, Littleton, $\mathrm{CO}$, United States) antibodies.

\section{Chicken Chorioallantoic Membrane Assay}

The effect of metformin and pemetrexed on angiogenesis was evaluated using the CAM assay, following a method with minor modification. Fertilized chicken eggs were maintained in a humidified egg incubator at $37^{\circ} \mathrm{C}$. After 3 days of incubation, a small hole was made using an 18-gauge needle to extract $4 \mathrm{ml}$ of albumin from the egg. An approximate $1-\mathrm{cm}^{2}$ window was created to check the health and normal growth of the embryos and to exclude malformations or dead embryos. After fenestration, the windows were sealed with tape to prevent contamination and placed back into the incubator. On day 7 of the incubation, $5 \times 10^{6}$ A549 cells suspended in $30 \mu \mathrm{l}$ of $50 \%$ Matrigel (BD Biosciences) were directly seeded on the membrane of CAM through the small window created earlier. The cells were then treated with $40 \mu \mathrm{l}$ metformin (Met; $0.1 \mathrm{mg} / \mathrm{egg}$ ), pemetrexed (Pem; $0.01 \mathrm{mg} / \mathrm{egg}$ ), or both (Met; $0.1 \mathrm{mg} / \mathrm{egg}+$ Pem; $0.01 \mathrm{mg} / \mathrm{egg}$ ) for $48 \mathrm{~h}$, and the cultures had a replacement of fresh drug and culture medium every 2 days. After cell grafting and treatment, the windows were covered again, and the eggs were placed back into the incubator. After a 7-day period of treatment, each egg was observed, and the blood vessels were photographed. The antiangiogenic effects of metformin and pemetrexed on the CAMs were quantified, and the mean vessel area was quantified as a percentage of the total area (vessel density), total vessel length and the number of branch points, which were estimated using WimCAM software (Onimagin Technologies, Cordoba, Spain).

\section{RNA Isolation and RT-qPCR}

Total RNA was isolated from at least two FFPE lung tissue blocks, as previously described (Körbler et al., 2003). Briefly, sections were deparaffinized by immersion in xylene twice for $15 \mathrm{~min}$ at room temperature with agitation, followed by two rounds of centrifugation for $2 \mathrm{~min}$ at $10,000 \times g$. Then, rehydration steps were performed (rinsing twice in $100 \%$ ethanol and once in 95,80 , and $60 \%$ ethanol). After each step, the tissue was harvested by centrifugation at $10,000 \times g$ for $10 \mathrm{~min}$. Then, the pellets were resuspended in $500 \mu \mathrm{l}$ digestion buffer $[10 \mathrm{mM}$ $\mathrm{NaCl}, 500 \mathrm{mM}$ Tris ( $\mathrm{pH}$ 7.6), $20 \mathrm{mM}$ EDTA, and 1\% SDS] and $500 \mu \mathrm{g} / \mathrm{ml}$ proteinase $\mathrm{K}$ and incubated at $45^{\circ} \mathrm{C}$ overnight. Prior to RNA purification, in some samples, we inactivated 
proteinase $\mathrm{K}$ at $100^{\circ} \mathrm{C}$ for $7 \mathrm{~min}$. The subsequent protocol for total RNA extraction was the same as for the TRIzol reagent (Life Technologies), according to the manufacturer's instructions (Tung et al., 2015). The mRNAs were reverse transcribed into cDNA, and RT-qPCR was performed as previously described (Lan et al., 2017). The sequences of the specific primers used are listed in Table 1. Relative gene expression was determined by the $\Delta \Delta \mathrm{Ct}$ method, where $\mathrm{Ct}$ was the threshold cycle. The relative mRNA expression levels were normalized to the housekeeping genes.

\section{Orthotopic Xenografts}

Eight-week-old male nude mice (BALB/cAnN. Cg-Foxnlnu/ CrlNARL) were purchased from the National Laboratory Animal Center (Taipei, Taiwan) and fed with the purified rodent diet AIN76A (Research Diets, New Brunswick, NJ, United States) to reduce autofluorescence. Orthotopic xenografts of the A549 cell suspension $\left(1 \times 10^{6}\right.$ A549 cells suspended in 50\% Matrigel; $\mathrm{v} / \mathrm{v}=1: 1)$ were generated through transpleural injection as previously described (Lai et al., 2016). The animal experiments were approved by the Institutional Animal Care and Use Committee of National Chung Hsing University (IACUC no. 105-070) and were carried out in compliance with institutional guidelines.

\section{In vivo Imaging and Quantification of Lung Tumors}

After 4 weeks of A549 cell grafting, mice were randomly selected for oral gavage with metformin (Met; $250 \mathrm{mg} / \mathrm{kg} /$ day), intraperitoneal injection of pemetrexed (Pem; $150 \mathrm{mg} / \mathrm{kg} / \mathrm{twice}$ a week), or both (Met + Pem). The dosage and delivered route were based on previous studies (Steiner et al., 2007; Gong et al., 2020). On week 3, after drug treatment, the iRFP fluorescence was detected by an IVIS ${ }^{\circledR}$ Spectrum CT instrument (PerkinElmer,

TABLE 1 | Oligonucleotide primers used for RT-qPCR analysis.

\begin{tabular}{|c|c|c|}
\hline Primer set & Oligonucleotide sequence & Size (bp) \\
\hline \multirow[t]{2}{*}{ GFP } & Forward: ACC GGG GTG GTG CCC ATC CT & 314 \\
\hline & Reverse: TTC ACC TCG GCG CGG GTC TT & \\
\hline \multirow[t]{2}{*}{ mVEGFA } & Forward: CTG TGC AGG CTG CTG TAA C & 184 \\
\hline & Reverse: ACA GTG ATT TTC TGG CTT TGT TC & \\
\hline \multirow[t]{2}{*}{ mEndoglin } & Forward: CCC TCT GCC CAT TAC CCT G & 120 \\
\hline & Reverse: GTA AAC GTC ACC TCA CCC CTT & \\
\hline \multirow[t]{2}{*}{ mGAPDH } & Forward: TGA CCT CAA CTA CAT GGT CTA CA & 85 \\
\hline & Reverse: CTT CCC ATT CTC GGC CTT G & \\
\hline \multirow[t]{2}{*}{ hCEACAM5 } & Forward: CTG TCC AAT GAC AAC AGG ACC & 174 \\
\hline & Reverse: ACG GTA ATA GGT GTA TGA GGG G & \\
\hline \multirow[t]{2}{*}{ hcyclinA2 } & Forward: GGA TGG TAG TाT TGA GTC ACC AC & 202 \\
\hline & Reverse: CAC GAG GAT AGC TCT CAT ACT GT & \\
\hline \multirow[t]{2}{*}{ hcyclinD1 } & Forward: TCT CCA AAA TGC CAG AGG CG & 178 \\
\hline & Reverse: AGG AAG TTG TTG GGG СTC СТ & \\
\hline \multirow[t]{2}{*}{ hCDKN1B } & Forward: ATAAGGAAGCGACCTGCAACCG & 119 \\
\hline & Reverse: TTC TTG GGC GTC TGC TCC ACA G & \\
\hline \multirow[t]{2}{*}{$h \beta$-actin } & Forward: GCG AGA AGA TGA CCC AGA TC & 103 \\
\hline & Reverse: CCA GTG GTA CGG CCA GAG G & \\
\hline
\end{tabular}

Richmond, CA, United States) with Ex/Em wavelength filters set at $675 / 720 \mathrm{~nm}$. A fixed region of interest (ROI) was selected in the mouse chest to obtain the total radiant efficiency $\left[(\mathrm{p} / \mathrm{s}) /\left(\mu \mathrm{W} / \mathrm{cm}^{2}\right)\right]$ values of the iRFP fluorescence and then quantified by Living Image software (PerkinElmer). Then, blood and lung tissues were collected for further examination.

\section{Enzyme-Linked Immunosorbent Assay}

We performed Enzyme-linked immunosorbent assays (ELISAs) for the assessment of Endoglin (R\&D Systems, Minneapolis, MN, United States), VEGF (Sigma-Aldrich), and CEA (Abcam) according to the manufacturers' protocols.

\section{Histopathological Staining}

The lung samples were fixed in $10 \%$ formalin and embedded in paraffin sections before staining with hematoxylin and eosin (Sigma-Aldrich) according to standard protocols.

\section{Immunofluorescent Staining}

Lung samples were cut into $4 \mu \mathrm{m}$ thick sections and taken from along the maximum area axis of the lobe. IF staining of the paraffin-fixed sections to evaluate the amount of engrafted A549-iRFP-2A-Venus cell growth in vivo was performed. The deparaffinized sections were blocked with $4 \%$ bovine serum albumin (Sigma-Aldrich) in PBS with $0.2 \%$ Triton X-100 for $2 \mathrm{~h}$ at room temperature. Sections were then incubated overnight at $4^{\circ} \mathrm{C}$ with an anti-VEGF-A antibody (1:40; Novus Biologicals, Littleton, CO, United States) or anti-PECAM1 antibody (1:50; Arigo Biolaboratories, Hsinchu City, Taiwan). Sections were incubated with secondary antibody (Alexa Fluor ${ }^{\circledR}$ 546conjugated goat anti-rabbit IgG) for $1 \mathrm{~h}$ at room temperature. After washing with PBS, the slides were stained with DAPI for nuclear counterstaining and mounted with low viscosity aqueous mount (ScyTek Laboratories, Logan, UT, United States), after which fluorescence microscopy was used for capture and analysis.

\section{Statistical Analysis}

All data are represented as the mean \pm SD. For multiple comparisons, one-way analysis of variance analysis will be used, followed by the Tukey's post hoc test for analyzing parametric data. All statistical analyses will be performed using GraphPad 8.0 Prism (GraphPad Software, Inc., San Diego, CA, United States). $P<0.05$ represents statistical significance.

\section{RESULTS}

\section{Additive Antiproliferative Effect of the Combination of Metformin and Pemetrexed in NSCLC Cell Lines}

We analyzed and confirmed the antiproliferative function of metformin alone $(0.2 \mathrm{mM})$, pemetrexed alone $(1 \mu \mathrm{M})$ or a combination in the A549, H1975, and HCC 827 cell line model by the MTT method. After $48 \mathrm{~h}$ of treatment, the use of metformin or pemetrexed alone showed significant decreases in A549 and H1975 cell number compared to the control group, but there was 

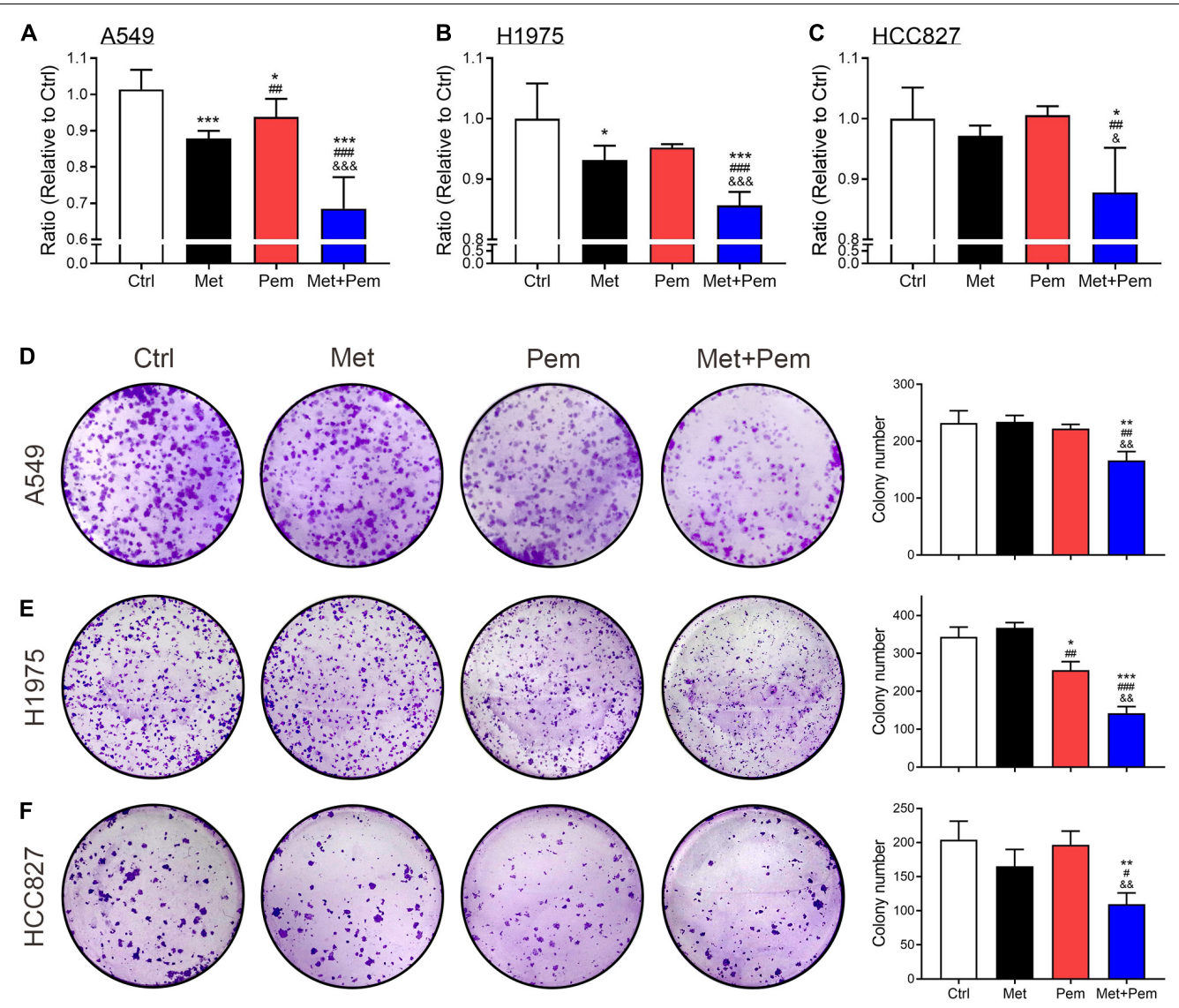

FIGURE 1 | Additive antiproliferative effects of metformin and pemetrexed in the NSCLC cell lines. An MTT assay was used to detect the growth of (A) A549, (B) $\mathrm{H} 1975$, and (C) HCC827 cells treated with metformin $(0.2 \mathrm{mM})$ and/or pemetrexed $(1 \mu \mathrm{M})$ for $48 \mathrm{~h}$. The ratio of the cell proliferation rate relative to control was calculated. (D-F) A colony formation assay was performed. Three cell lines were seeded at low density (1,000 cells/well) in 12-well plates. After $24 \mathrm{~h}$ of adhesion, the cells were treated with metformin and/or pemetrexed for 10 days. The colonies were stained with crystal violet. Representative photographs of each well were taken with a camera. [(D-F), right panel] Quantification of the cell colonies by imaging software. The data are presented as the mean \pm SD of those from three independent experiments with three technical replicates in each. ${ }^{\star} P<0.05$, ${ }^{\star \star} P<0.01$, and ${ }^{\star \star \star} P<0.001$ compared with the Ctrl group; ${ }^{\#} P<0.05$, ${ }^{\# \#} P<0.01$, and ${ }^{\# \# \# P}<0.001$ compared with the Met group; ${ }^{*} P<0.05$, ${ }^{\&} \& P<0.01$, and $\& \& \& P<0.001$ compared with the Pem group.

a more significant reduction in the metformin and pemetrexed combination group (Figures 1A,B). The HCC827 cell number showed no change between control and the use of metformin or pemetrexed alone groups, but there was a significant reduction in the metformin and pemetrexed combination group (Figure 1C). We also checked the colony formation units (CFUs) in the four groups in three cell lines and quantitatively analyzed them (Figures 1D-F). Three cell lines showed similar results that much less colony formation, an approximately $50 \%$ reduction, in the metformin and pemetrexed combination group than in the control and single drug groups.

\section{Additive Cell Cycle Arrest Effect of the Combination of Metformin and Pemetrexed in NSCLC Cell Lines Through Modulating AMPK-AKT Signaling}

Mounting evidence have shown the half maximal inhibitory concentration (IC50) of metformin and pemetrexed in NSCLC cell lines, the IC50 values at $48 \mathrm{~h}$ of metformin was $1-10 \mathrm{mM}$ and the pemetrexed was 1.5-3.5 $\mu \mathrm{M}$ (Zhang et al., 2017). To investigate the potential mechanism by which lower dosage of metformin and pemetrexed influence NSCLC cell growth, we analyzed the cell cycle and apoptosis. In three NSCLC cell lines and normal lung cells (WI38-2RA), the flow cytometric analysis of propidium iodide (PI)-labeled cells showed that the cells accumulated in the $S$ phase after single pemetrexed treatment (Figures 2A-D); however, in the combination of metformin and pemetrexed-treated NSCLC cells showed more significant cells arrested in the $\mathrm{S}$ phase than single pemetrexed treatment groups (Figures 2A-C). In the WI38-2RA cell, no significant change between combination treatment or single pemetrexed treatment group (Figure 2D).

In Figure 2E, we found that apoptosis rates of three NSCLC cell lines and normal lung cells treated with metformin alone $(0.2 \mathrm{mM})$, pemetrexed alone $(1 \mu \mathrm{M})$ or a combination were less than 3\%. Although a statistical increase in H1975 apoptotic cells treated with single pemetrexed treatment and combination treatment compared to control group, a trend 

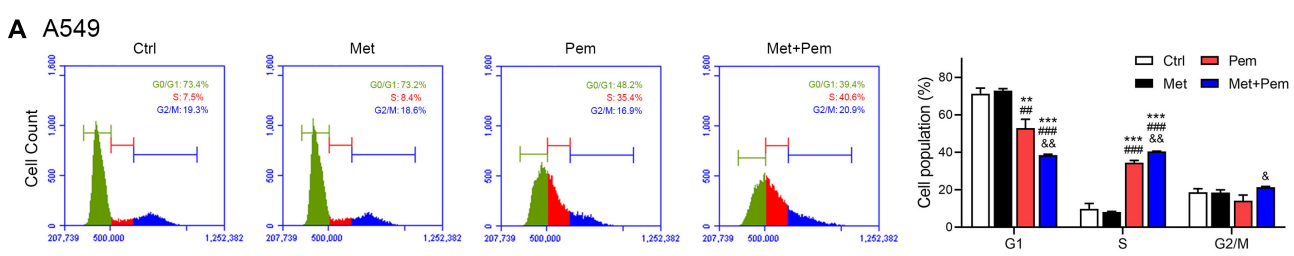

B $\mathrm{H} 1975$
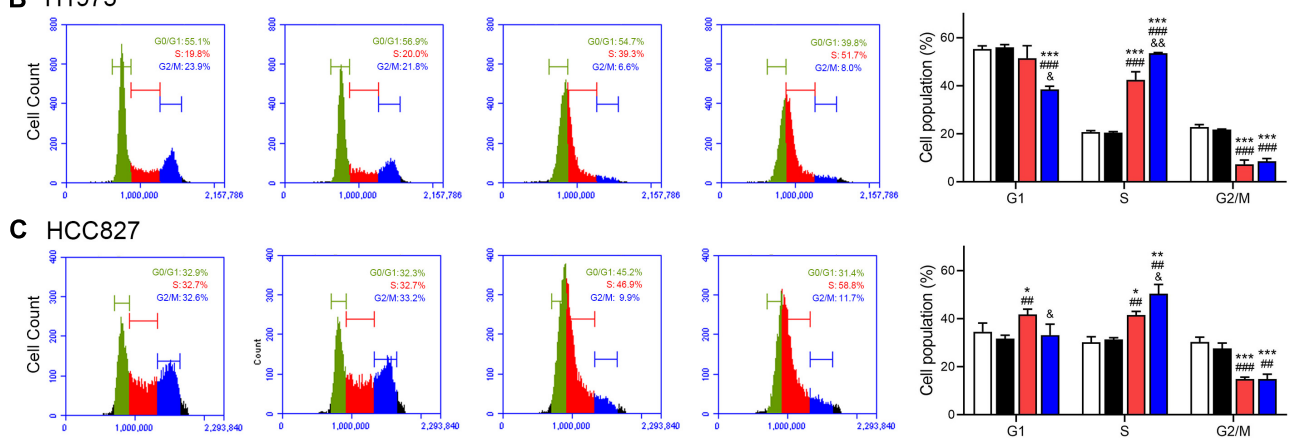

D WI38-2RA
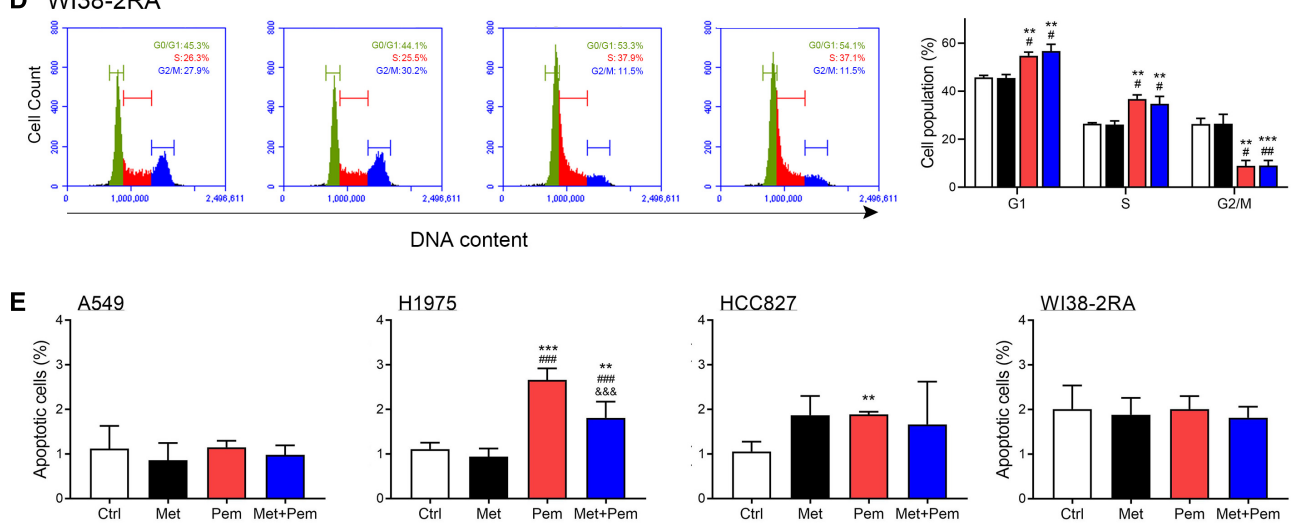

FIGURE 2 | Additive cell cycle arrest and apoptosis effects of metformin and pemetrexed on the NSCLC and normal lung cell lines. Flow cytometric analysis and the cell cycle distribution of (A) A549, (B) H1975, (C) HCC827, and (D) WI38-2RA cells treated with metformin (0.2 mM) and/or pemetrexed (1 $\mu$ M) for 48 h. (A-D, right panel) Quantification of cell cycle distribution. (E) Cytotoxicity of A549, H1975, HCC827, and WI38-2RA treated with the indicated concentration of metformin and/or pemetrexed for $48 \mathrm{~h}$ as assessed by flow cytometric analysis with Annexin V/propidium iodide (PI) staining. Percentages of Annexin V-positive cells (apoptosis cells population) are shown. The data are presented as the mean \pm SD of those from three independent experiments with three technical replicates in each. ${ }^{\star} P<0.05$, ${ }^{\star *} P<0.01$, and ${ }^{\star \star \star} P<0.001$ compared with the Ctrl group; ${ }^{\#} P<0.05$, ${ }^{\#} P<0.01$, and ${ }^{\# \# \# ~} P<0.001$ compared with the Met group; \& $P<0.05$, \&\& $P<0.01$, and $\& \& \& P<0.001$ compared with the Pem group.

was not evident. Taken together, low dosage of metformin and pemetrexed showed extreme low cytotoxic effect on normal lung cells and three NSCLC cell lines. The combination treatment of metformin and pemetrexed exerted an additive antiproliferative effect in three NSCLC cell lines we used with either wild type epidermal growth factor receptor (EGFR; A549) or mutant type EGFR (H1975 and HCC827). Therefore, NSCLC cell line with wild type EGFR (A549) was used for the following experiments.

Downregulation of cyclin D1, cyclin A2 and pAKT and upregulation of CDKN1B expression caused cell cycle arrest in the S phase (Cai et al., 2018). Western blot analysis showed that phosphorylated AMPK expression level significantly increased, which were further increased in the combination treatment groups. The expression level of phosphorylated AKT also significantly decreased in the combination treatment groups (Figures 3A,B). Hence, cell cycle regulatory molecules expression level also detected by using western blot and RT-qPCR analysis. Results showed that the combination of metformin and pemetrexed significantly downregulated cyclin D1 and cyclin A2 expression and upregulated CDKN1B expression, possibly through activated AMPK pathway to downregulate AKT signaling (Figure 3).

\section{Additive Antiangiogenic Effect of the Combination of Metformin and Pemetrexed in an ex vivo Chicken Embryo Chorioallantoic Membrane Assay}

For angiogenesis models, the CAM assay is a popular choice. We chose chicken embryos and established A549 xenograft 

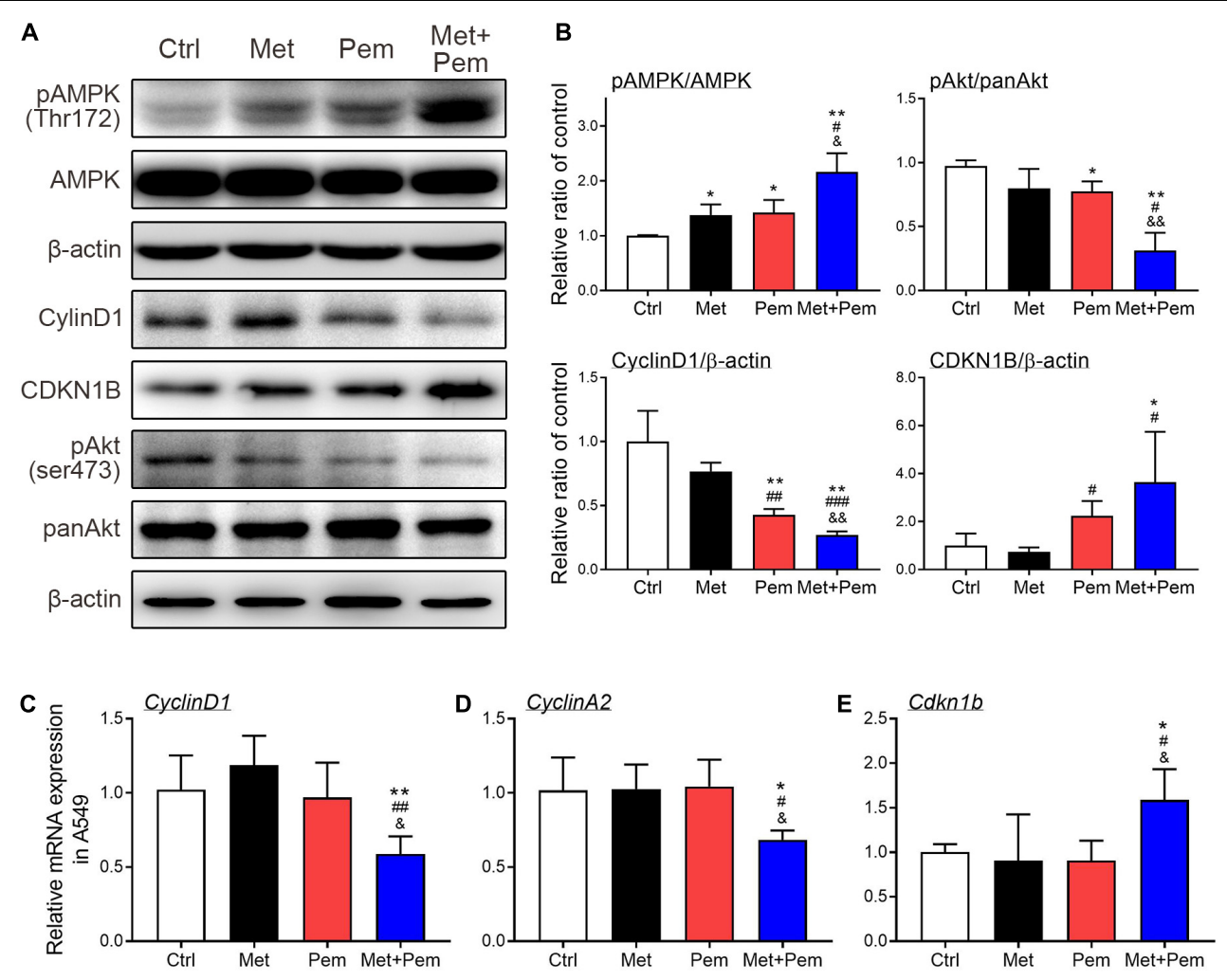

FIGURE 3 | Additive cell cycle arrest of metformin and pemetrexed on A549 cell line through modulating AMPK-AKT signaling. (A) Western blotting was performed to detect the expression of pAMPK/AMPK, pAKT/panAKT, cyclin D1 and CDKN1B in the A549 cell line. Human $\beta$-actin was used as the normalization control. (B) Values were normalized to human $\beta$-actin levels and expressed relative to the control. RT-qPCR was performed to analyze (C) cyclin D1, (D) cyclin A2, and (E) CDKN1B. Values were normalized to the $\beta$-actin gene and expressed in relation to the control. Data are presented as the mean \pm SD of those from three independent experiments with two technical replicates in each. ${ }^{\star} P<0.05$ and ${ }^{\star \star} P<0.01$ compared with the Ctrl group; ${ }^{\#} P<0.05$, ${ }^{\# \#} P<0.01$ and ${ }^{\# \# \#} P<0.001$ compared with the Met group; ${ }^{\&} P<0.05$ and ${ }^{\& \&} P<0.01$ compared with the Pem group.

models in five groups, followed by the addition of metformin (0.1 mg/egg) and/or pemetrexed (0.02 mg/egg) separately. After 7 days of treatment, macroscopic observation showed that blood vessel density significantly decreased in the metformin and pemetrexed combination groups (Figure 4A, upper panel). WimCAM analysis (Figure 4A, lower panel) was used for quantitative analysis and provided a statistical bar chart for blood vessel density (Figure 4B), total blood vessel network length (Figure 4C), number of branching points (Figure 4D) and total blood vessel segments (Figure 4E) for the five groups (control, mock and three treatment groups). The results showed that the combination of metformin with pemetrexed significantly reduced angiogenesis and vessel growth compared with the mock or single treatment groups.

\section{In vivo Visualization and Quantification of the Additive Antitumor Growth Effect of the Combination of Metformin and Pemetrexed in an A549 Orthotopic Xenograft Model}

In our previous study, we established an A549 orthotopic xenograft model (Lai et al., 2016). After 4 weeks of A549 grafting, the mice were treated with metformin (Met; $250 \mathrm{mg} / \mathrm{kg} /$ day), pemetrexed (Pem; 150 mg/kg/twice a week), or both (Met + Pem) for 3 weeks. We recorded tumor size with the aid of IVIS (a Spectrum CT instrument) and quantitatively analyzed the total radiant efficiency of the region of interest (ROI) in each group (Figure 5A). This showed decreased total radiant efficiency in the combination treatment group (Figure 5A, left panel). After sacrifice of the mice, we performed ex vivo fluorescence imaging and observed the results directly through the IVIS Spectrum system (Figure 5B, left panel). The quantitative analysis showed a reduction in total radiant efficiency after the combination of metformin and pemetrexed treatment (Figure 5B, right panel).

\section{The Combination of Metformin With Pemetrexed Exerted Additive Inhibitory Effects on Pulmonary Tumorigenesis and Antiangiogenic Effects in an A549 Orthotopic Xenograft Model}

We further analyzed the angiogenesis associated indicators involved in tumorigenesis by our A549 orthotopic NSCLC xenograft model. After 3 weeks of treatment, we checked the histopathologic findings, including hematoxylin and eosin 
A
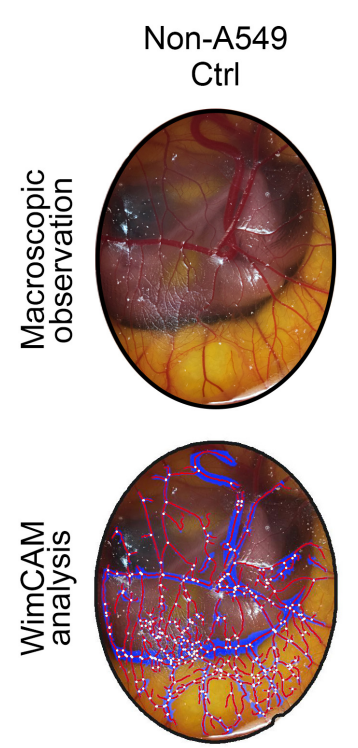

A549

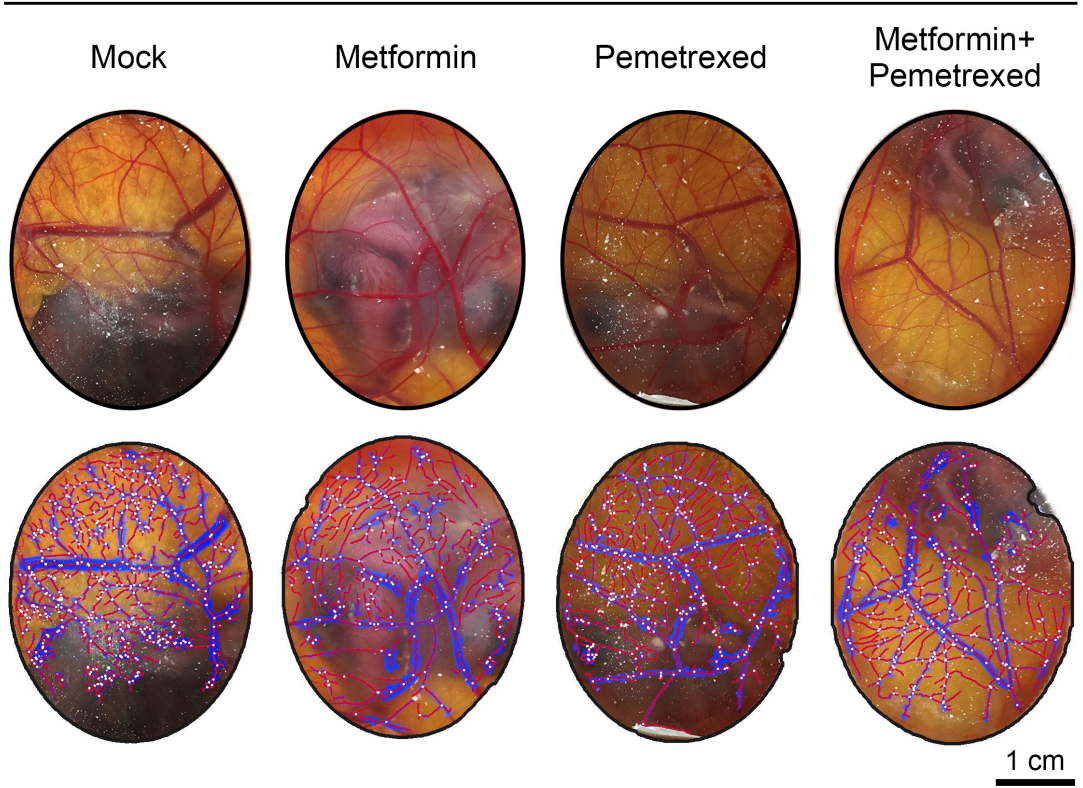

B

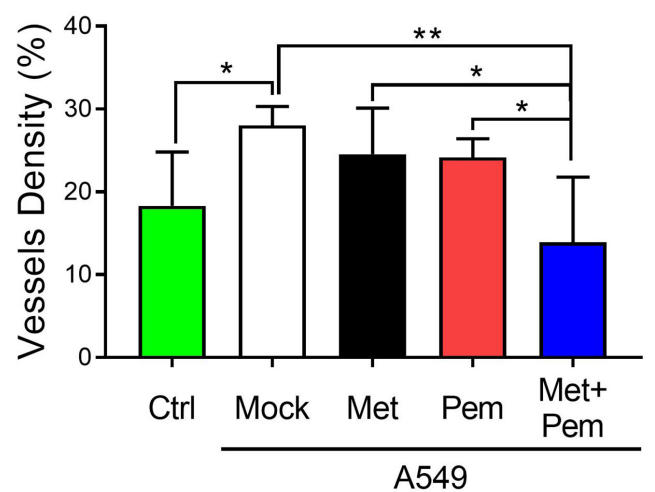

D

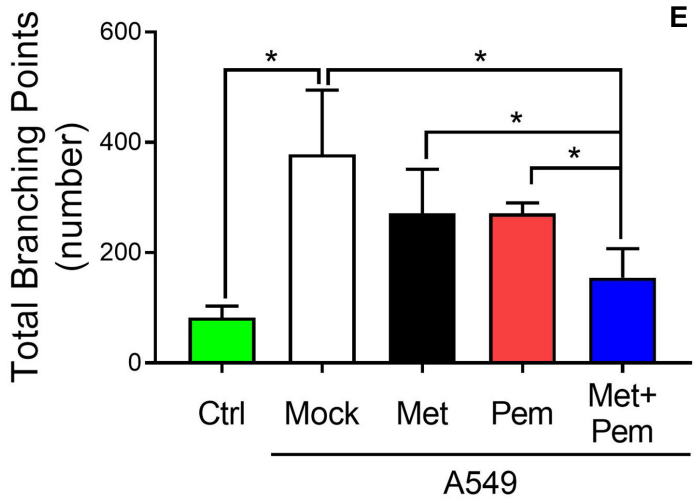

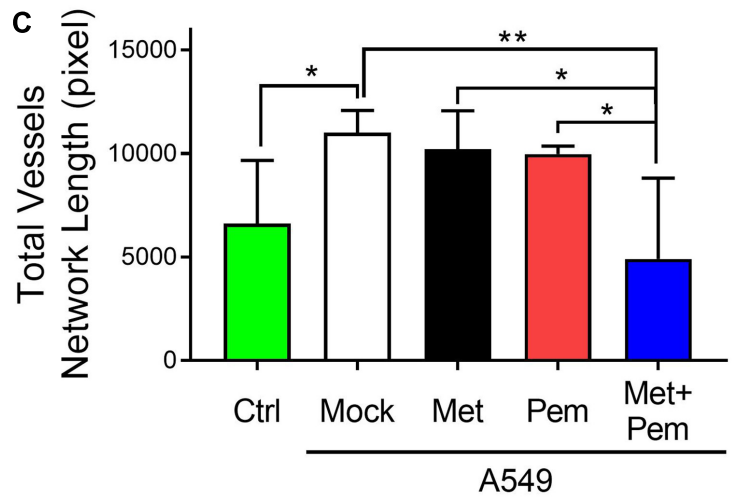

E

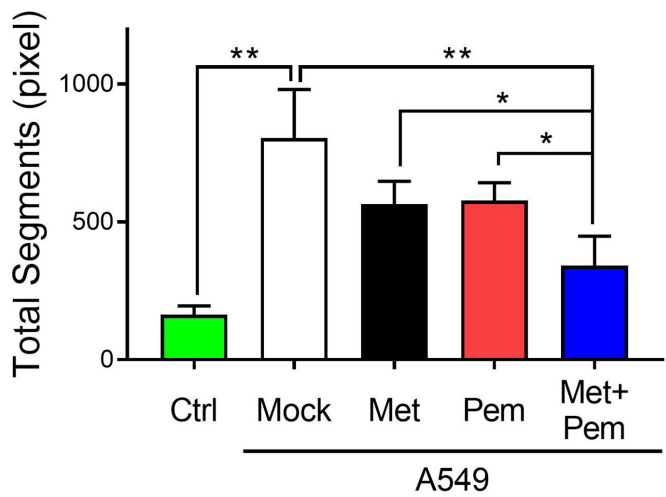

FIGURE 4 | The combination of metformin with pemetrexed attenuated A549 cell-induced angiogenesis in a chick embryo chorioallantoic membrane (CAM) assay. (A) The upper panel shows the blood vessel plexus of 14-day-old chicken embryos following A549 xenograft metformin (0.1 mg/egg) and/or pemetrexed (0.02 mg/egg) treatment. The lower panel shows the WimCAM analysis results in which vessel structure (blue), vessel skeleton (red) and branching points (white) are marked. The statistical bar chart shows (B) blood vessel density, (C) total blood vessel network length, (D) number of branching points, and (E) total blood vessel segments for the control, mock and treatment groups. Scale bars $=1 \mathrm{~cm}$. Data are presented as the mean $\pm \mathrm{SD}$. those from 3-4 independent experiments with two technical replicates in each. ${ }^{*} P<0.05$ and ${ }^{* *} P<0.01$. 

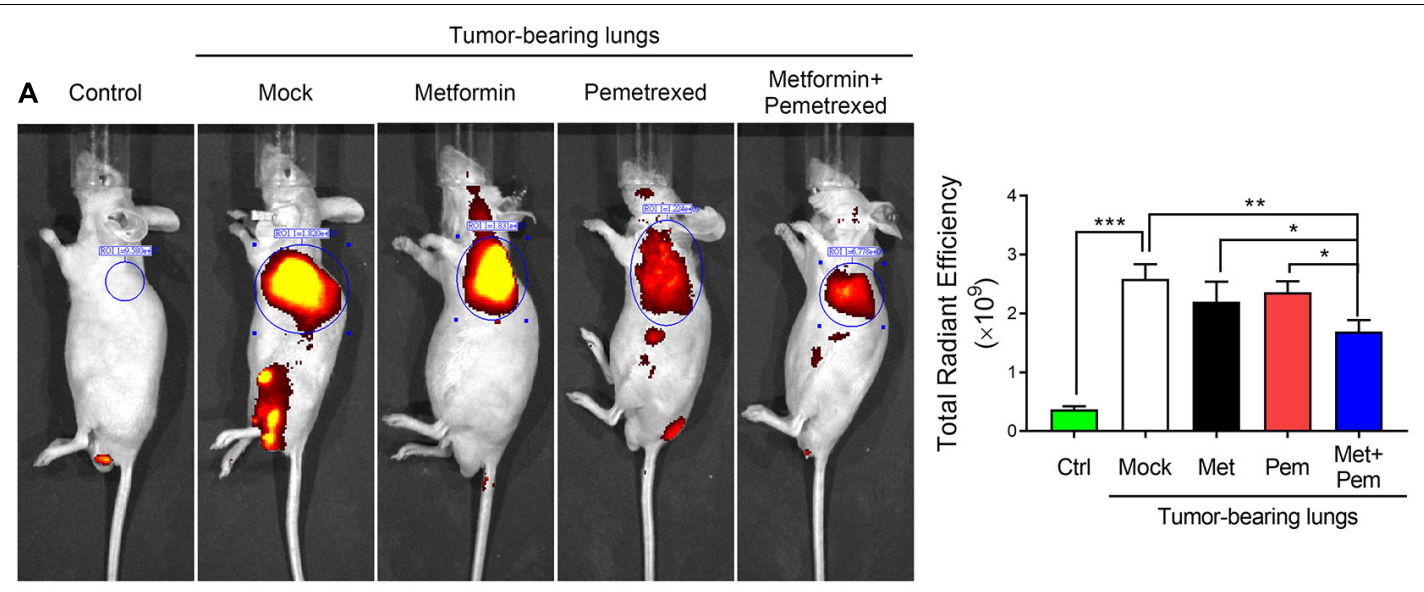

B
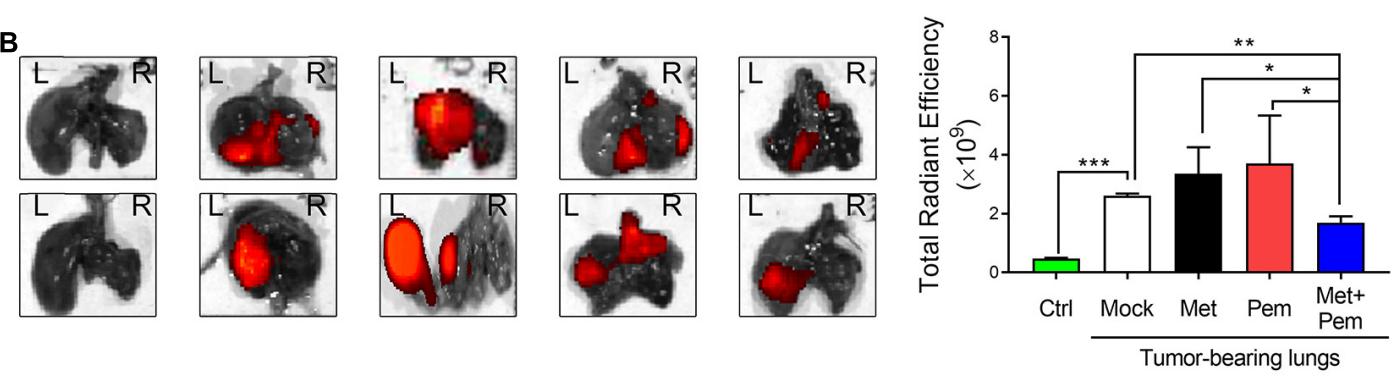

FIGURE 5 | The combination of metformin with pemetrexed exerted additive inhibitory effects on A549 cell growth in a human orthotopic NSCLC xenograft model. An orthotopic lung tumor model was established via transpleural injection of $1 \times 10^{6}$ fluorescently labeled A549 cells (iRFP-2A-Venus). After 4 weeks of A549 grafting, the mice were treated with metformin (Met; $250 \mathrm{mg} / \mathrm{kg} /$ day), pemetrexed (Pem; $150 \mathrm{mg} / \mathrm{kg} / \mathrm{twice}$ a week) or both (Met + Pem). [(A) left panel] After a 3-week period of drug treatment, in vivo fluorescence images were acquired using an IVIS ${ }^{\circledR}$ (Spectrum CT instrument) at the appropriate wavelength (iRFP: $\lambda$ 650/720 nm). [(A) right panel] Statistical bar chart shows the total radiant efficiency of the iRFP signals, which was calculated using Living Image software. [(B) left panel] Whole lungs were excised from nude mice, and ex vivo fluorescence imaging was observed directly through the IVIS Spectrum system. [(B) right panel] Quantitative analysis of fluorescence intensity based on ex vivo images. All images were scaled to the same minimum and maxi-mum color values. The data are presented as the mean \pm SD of those from 2-3 independent experiments with two technical replicates in each. ${ }^{*} P<0.05,{ }^{* *} P<0.01$, and ${ }^{* * *} P<0.001$.

(H\&E) staining (Figure 6A) and immunofluorescence (IF) staining of VEGF and PECAM-1, a marker of endothelial cells (Figures 6B-E). The percentage of VEGF-positive area significantly increased in the A549 tumor-bearing lung (mock group) and single metformin treatment group; however, single pemetrexed treatment decreased the percentage of VEGFpositive area, which were further decreased in the combination treatment groups (Figure 6D). In addition, the percentage of PECAM-1-positive area significantly higher in the mock and single treatment groups; however, a significant less PECAM1-positive area was detected in the combination treatment group, indicating less presence of endothelium of blood vessels formation within the lung tumor site (Figure 6E).

Moreover, all the mRNA expression levels of the angiogenic indicators Endoglin (Figure 7A) and Vegfa (Figure 7B), along with those of tumor marker carcinoembryonic antigen (CEACAM5) (Figure 7C) and green fluorescent protein (GFP) (Figure 7D), in the lung tissues of mice showed significant downregulation in the metformin and pemetrexed combination treatment group. Among the different indicators, we proved the obvious additive effect of combined metformin and pemetrexed on VEGFA expression. This indicates that the combination of metformin and pemetrexed truly targeted the angiogenesis pathway. In addition, we checked the expression of Endoglin (Figure 7E), VEGF (Figure 7F) and human CEA (Figure 7G) in the serum of the mice by ELISA kits. Taken together, the combination of metformin and pemetrexed had an impact on reducing the expression of the above indicators compared with the mock and single treatment groups.

\section{DISCUSSION}

From the experimental results, we found that the combination of metformin and pemetrexed exerted additive antitumor effects via in vitro, ex vivo, and in vivo models. In three NSCLC cell lines model, when metformin was added to pemetrexed, an antiproliferative effect was observed through the inhibition of colony formation (Figure 1), as well as an induced cell cycle arrest (G1/S phase) (Figure 2) through regulating the AMPK/AKT signaling pathway (Figure 3). In a chicken embryo chorioallantoic membrane (CAM) assay (ex vivo model), metformin combined with pemetrexed was shown to be antiangiogenic by reducing vessel density, network formation and microenvironment formation. The antiangiogenic effect was also validated in our orthotopic NSCLC xenograft model, which 


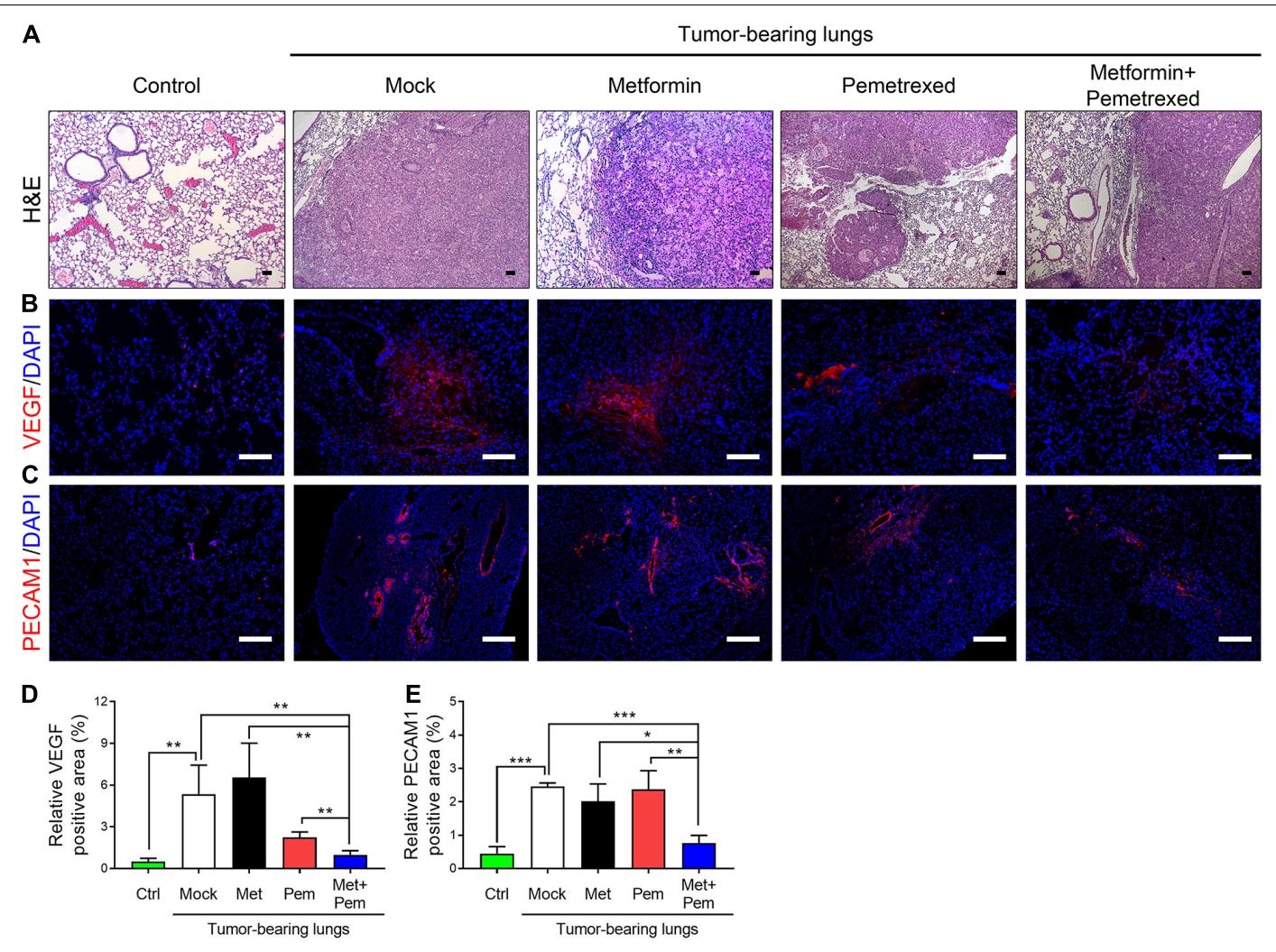

FIGURE 6 | The combination of metformin with pemetrexed exerted additive inhibitory effects on pulmonary tumorigenesis in a human orthotopic NSCLC xenograft model. (A) H\&E staining, immunofluorescence staining for (B) VEGF (red), (C) PECAM1 (red) and nuclei (DAPI; blue) in nude mouse lung tissues after a 3 week treatment period with metformin (Met; 250 mg/kg/day), pemetrexed (Pem; 150 mg/kg/twice a week) or both (Met + Pem) following a 4 week A549 cell xenograft. Scale bar $=100 \mu \mathrm{m}$. The area of (D) VEGF and (E) PECAM1 positive signal were calculated in three field from three independent experiments and represented as\% of positive area. The data are presented as the mean \pm SD of those from $2-3$ independent experiments with two technical replicates in each. ${ }^{\star} P<0.05$, ${ }^{\star *} P<0.01$, and ${ }^{\star \star \star} P<0.001$
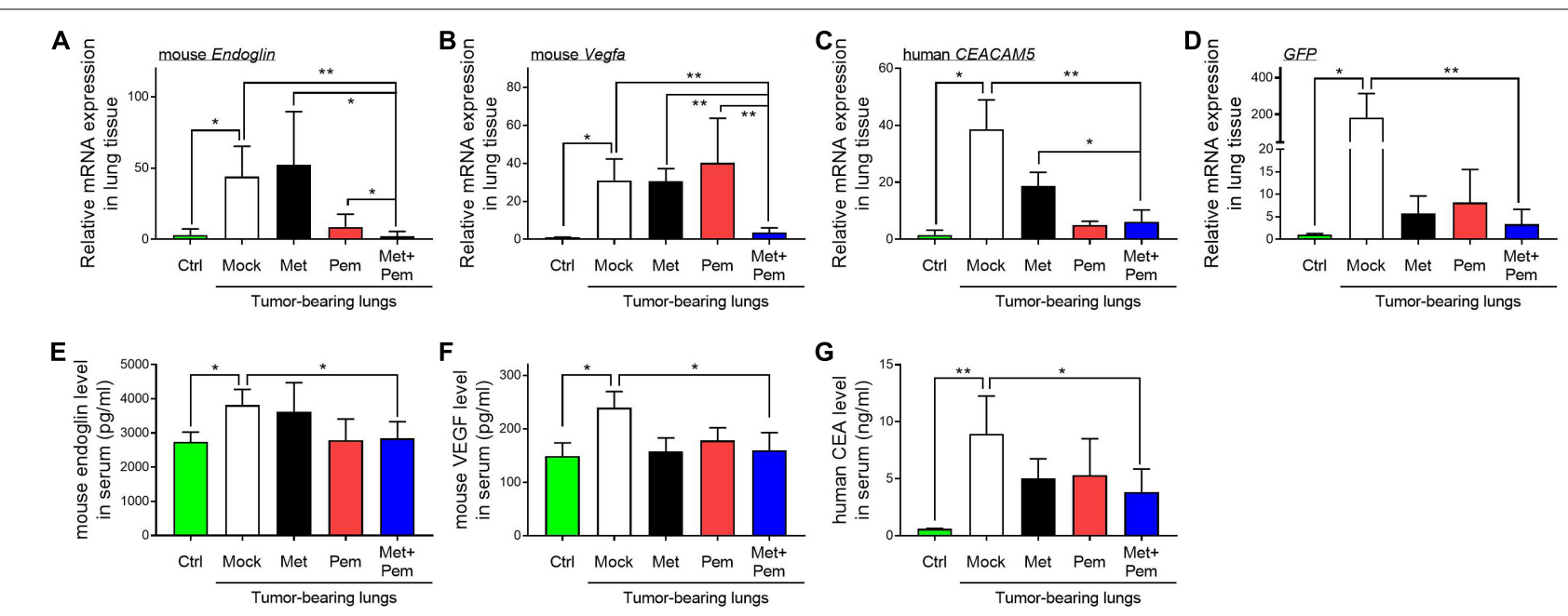

FIGURE 7 | Molecule expression related to the metformin/pemetrexed additive inhibitory effects on pulmonary tumorigenesis and angiogenesis in a human orthotopic NSCLC xenograft model. RT-qPCR was performed to analyze the expression of angiogenic indicators (A) Endoglin and (B) Vegfa, tumor marker (C) carcinoembryonic antigen (CEACAM5), and (D) GFP in the lung tissues of mice that received different treatments. Values were normalized to GAPDH levels and are expressed relative to the control group. The expression levels of (E) Endoglin, (F) VEGF and (G) human CEA in the serum of the mice were determined using ELISA kits. The data are presented as the mean \pm SD of those from 2-3 independent experiments with two technical replicates in each. ${ }^{\star} P<0.05$ and ${ }^{\star \star} P<0.01$. 
included real-time imaging (IVIS) and in vivo analysis of VEGFassociated angiogenic indicators.

Previous literature has reviewed the scope of the potential antitumor effect of the use of metformin alone or as an adjuvant to other anticancer modalities, including chemotherapeutic reagents (Peng et al., 2017; Levy and Doyen, 2018; Fatehi Hassanabad and MacQueen, 2020). Activation of the AMPKdependent pathway has been extensively discussed (Zakikhani et al., 2006; Emami Riedmaier et al., 2013; Sinnett-Smith et al., 2013). Once AMPK is activated, it phosphorylates and activates tuberous sclerosis complex 2 (TSC2). This leads to the subsequent negative regulation of the mTOR pathway with the help of liver kinase B1 (LKB1) to induce an antiproliferative effect (Shaw et al., 2005). The mTOR pathway is the core for cell proliferation and protein formation (Sinnett-Smith et al., 2013). It can also be upregulated via the phosphoinositide 3-kinase/protein kinase B/AKT (PI3K/PKB/AKT) pathway. Metformin can target the mTOR pathway by activating AMPK to inhibit tumorigenesis by decreasing cancer cell proliferation (Gwinn et al., 2008; Emami Riedmaier et al., 2013; Sinnett-Smith et al., 2013). In cell cycle regulation, Kato et al. (2012) and Rattan et al. (2011) showed that metformin can reduce the expression of cyclin D1, CDK4 and CDK6 in ovarian and gastric cancer cell lines and xenograft models. The additional inhibition of the expression of cyclin D1 and retinoblastoma protein was also mentioned (Ben Sahra et al., 2008).

Metformin can also enhance p53-mediated cell cycle arrest via the AMPK-related apoptosis pathway (Buzzai et al., 2007; Emami Riedmaier et al., 2013). In an in vitro study of A549, H1975, and HCC827 lung cancer cell lines, Zhang et al. (2017) found that metformin combined with pemetrexed not only inhibited cell proliferation but also induced cell apoptosis, as validated by western blot analysis of reduced levels of an antiapoptotic molecule (Bcl-2) and elevated levels of a proapoptotic molecule (Bax). In our study, we showed a similar result as Gong et al. described (Steiner et al., 2007) that the single uses of low dosage of metformin show no antiproliferative or apoptotic effect on A549 cells. However, the combination of low dosage of metformin and pemetrexed reached an additive antiproliferative effect by reducing the expression of cyclin D1 and $\mathrm{A} 2$ and augmenting CDKN1B expression. The additive effect was based on regulation of the cell cycle involved in the G1/S phase.

Angiogenesis is crucial for tumor growth, development and distal metastasis (Tosetti et al., 2002; Weis and Cheresh, 2011; Albini et al., 2012; Wang et al., 2020). As the tumor enlarges, proangiogenic factors need to be established when exposed to a hypoxic environment. The key element for this is vascular endothelial growth factor. The VEGF family is composed of four subgroups: VEGF-A, VEGF-B, VEGF-C, and VEGF-D. VEGF-A has potent efficacy and has four isoforms, and VEGFA165 is the dominant isoform. The angiogenesis process and tumor development are related to VEGF-A165 formation. In our study, the combination of metformin with pemetrexed reduced VEGF-A expression. This also showed inhibition of angiogenesis by immunohistochemistry staining for VEGF and
PECAM1 (Figures 6B-E), similar to the finding of Rattan et al. (2011). Joe et al. (2015) found that metformin possesses an antiangiogenic effect in mouse oxygen-induced retinopathy and is undermodulated by reducing the vascular endothelial growth factor receptor Flk-1. Other research found that metformin can alter and regulate the downregulation of microRNA (miR)-21 by upregulating TGF- $\beta$ to enhance the antiangiogenic mechanism (Wang et al., 2020). Further exploration of the up-stream regulatory mechanism is indeed needed.

Endoglin, a cell membrane glycoprotein that represents the endothelium in angiogenesis, can serve as tumor metastasis and prognostic factors (Fonsatti et al., 2003a,b; Wang et al., 2018). In our study (Figures 7A-E), combined metformin and pemetrexed revealed the trend of reduced Endoglin expression in an orthotopic xenograft model via RT-qPCR and ELISA analysis. We performed a CAM assay (ex vivo model) to clearly observe the macroscopic angiogenic structure and evaluated vessel formation by WimCAM analysis. We reconfirmed the serial validation of the antiangiogenic effects of the combination of metformin and pemetrexed from ex vivo to in vivo orthotopic xenograft models. In our designed A549 orthotopic xenograft model, we discovered and recorded tumor formation by the IVIS method. Transpleural injection into primary lung tumorigenesis instead of a subcutaneous tumor model helped us to more closely monitor and audit the therapeutic response in situ, along with the great advantage of real-time image capture (Chen et al., 2017).

When metformin is used as adjuvant therapy for chemotherapeutic agents in lung cancer, it can have beneficial antitumor effects (Iliopoulos et al., 2011; Lin et al., 2013; Tseng et al., 2013; Parikh et al., 2019). It has shown potential efficacy and clinical tolerability. Parikh et al. (2017) proposed a pilot study of a phase II trial for the evaluation of metformin therapy combined with a first-line chemotherapeutic regimen (carboplatin and pemetrexed) in advanced non-diabetic NSCLC. A lower toxicity, low cost and good tolerance of metformin were observed during the dosage titration. Despite the small sample size, the study revealed the feasibility of applying metformin combined with pemetrexed in lung cancer patients (Parikh et al., 2017). Another randomized phase II study of chemotherapy (paclitaxel/carboplatin/bevacizumab) with/without metformin in chemotherapy-naive advanced or metastatic NSCLC groups showed an improved progression-free survival (PFS) (9.6 vs. 6.7 months, $P=0.024$ ), though no overall survival (OS) significant change was observed (Marrone et al., 2018). In a recent FAME trial, metformin and a fasting-mimicking diet (FMD) were exploited for their potential efficacy when combined with platinum-pemetrexed chemotherapy in advanced LKB1inactivated lung adenocarcinoma. This trial is still under way. The expected goal is to improve the median PFS from 7.6 months (chemotherapy alone) to 12 months (combined with metformin) (Vernieri et al., 2019).

Finally, our research highlights the related antitumor mechanism provided by metformin and pemetrexed in combination. In addition to AMPK-dependent pathwayrelated antiproliferative effects, we also showed antiangiogenic clues for potential additional and helpful support for advanced research involved in combination therapy. 


\section{CONCLUSION}

In this study, we proved the additive antiproliferative and antiangiogenic effects of the combination of metformin and pemetrexed in a lung cancer orthotopic xenograft model. From in vitro, ex vivo, and in vivo models, we found a new approach for investigating the antitumor mechanisms of metformin and pemetrexed. Further large-scale randomized trial aimed at lung cancer therapy, including a combination of metformin and pemetrexed, are encouraged and anticipated.

\section{DATA AVAILABILITY STATEMENT}

The original contributions presented in the study are included in the article/Supplementary Material, further inquiries can be directed to the corresponding author/s.

\section{ETHICS STATEMENT}

The animal experiments were approved by the Institutional Animal Care and Use Committee of National Chung Hsing University (IACUC no. 105-070).

\section{AUTHOR CONTRIBUTIONS}

J-LW, Y-WL, Y-TT, C-CY, and C-MC: conceptualization. J-LW, Y-WL, and Y-TT: methodology and visualization. J-LW: software. J-LW, TS, and Y-WL: validation. Y-WL, TS, and C-MC: formal analysis. J-LW, Y-WL, and Y-CC: investigation. Y-TT and Y-AT: resources. Y-AT, Y-WL, and C-MC: data curation. J-LW and Y-WL: writing original draft preparation. C-CY and C-MC: writing review and editing. C-MC: supervision. Y-CC and Y-WL: project administration. J-LW and C-MC: funding acquisition.

\section{REFERENCES}

Albini, A., Tosetti, F., Li, V. W., Noonan, D. M., and Li, W. W. (2012). Cancer prevention by targeting angiogenesis. Nat. Rev. Clin. Oncol. 9, 498-509. doi: 10.1038/nrclinonc. 2012.120

Arrieta, O., Varela-Santoyo, E., Soto-Perez-de-Celis, E., Sanchez-Reyes, R., De la Torre-Vallejo, M., Muniz-Hernandez, S., et al. (2016). Metformin use and its effect on survival in diabetic patients with advanced non-small cell lung cancer. BMC Cancer 16:633. doi: 10.1186/s12885-016-2658-6

Belani, C. P., Brodowicz, T., Ciuleanu, T. E., Krzakowski, M., Yang, S. H., Franke, F., et al. (2012a). Quality of life in patients with advanced non-small-cell lung cancer given maintenance treatment with pemetrexed versus placebo (H3EMC-JMEN): results from a randomised, double-blind, phase 3 study. Lancet Oncol. 13, 292-299. doi: 10.1016/S1470-2045(11)70339-4

Belani, C. P., Wu, Y. L., Chen, Y. M., Kim, J. H., Yang, S. H., Zhang, L., et al. (2012b). Efficacy and safety of pemetrexed maintenance therapy versus best supportive care in patients from East Asia with advanced, nonsquamous non-small cell lung cancer: an exploratory subgroup analysis of a global, randomized, phase 3 clinical trial. J. Thorac. Oncol. 7, 567-573. doi: 10.1097/JTO.0b013e31823d4f9d

Ben Sahra, I., Laurent, K., Loubat, A., Giorgetti-Peraldi, S., Colosetti, P., Auberger, P., et al. (2008). The antidiabetic drug metformin exerts an antitumoral effect in vitro and in vivo through a decrease of cyclin D1 level. Oncogene 27, 3576-3586. doi: 10.1038/sj.onc. 1211024
All authors have read and agreed to the published version of the manuscript.

\section{FUNDING}

This research was funded in part by grants from the Taichung Veterans General Hospital, Taiwan (TCVGH-1073204B) and the Rong-Hsing Cooperation Project (TCVGH-NCHU1027605, TCVGH-NCHU1047610, TCVGH-NCHU1067609, and TCVGH-NCHU1087615) and by financial support by the Higher Education Sprout Project from the Ministry of Education (MOE-110-S-0023-A) in Taiwan.

\section{ACKNOWLEDGMENTS}

We thank our colleagues, Gary Ro-Lin Chang and TungChou Tsai, in the Molecular Embryology \& DNA Methylation Laboratory, Department of Life Sciences, National Chung Hsing University for their help with discussions and technical issues.

\section{SUPPLEMENTARY MATERIAL}

The Supplementary Material for this article can be found online at: https://www.frontiersin.org/articles/10.3389/fcell.2021. 688062/full\#supplementary-material

Supplementary Figure 1 | Whole western blot images with densitometry readings. (A-H) Whole western blot images with all molecular weight markers depicted in Figure 3A. Molecular weight markers are indicated. The intensity values and calculated ratios of each targeted band of the Western blots depicted in $(\mathbf{A}-\mathbf{H})$.

Supplementary Figure 2 | All IVIS images of whole animals and isolated lungs used within the main text of Figure $\mathbf{5}$.

Berghmans, T., Dingemans, A. M., Hendriks, L. E. L., and Cadranel, J. (2020). Immunotherapy for nonsmall cell lung cancer: a new therapeutic algorithm. Eur. Respir. J. 55:1901907. doi: 10.1183/13 993003.01907-2019

Brancher, S., Stoer, N. C., Weiderpass, E., Damhuis, R. A. M., Johannesen, T. B., Botteri, E., et al. (2020). Metformin use and lung cancer survival: a populationbased study in Norway. Br. J. Cancer 124, 1018-1025. doi: 10.1038/s41416-02001186-9

Buzzai, M., Jones, R. G., Amaravadi, R. K., Lum, J. J., DeBerardinis, R. J., Zhao, F., et al. (2007). Systemic treatment with the antidiabetic drug metformin selectively impairs p53-deficient tumor cell growth. Cancer Res. 67, 6745-6752. doi: 10.1158/0008-5472.CAN-06-4447

Cai, J., Lu, W., Du, S., Guo, Z., Wang, H., Wei, W., et al. (2018). Tenascin-C modulates cell cycle progression to enhance tumour cell proliferation through AKT/FOXO1 signalling in pancreatic cancer. J. Cancer 9, 4449-4462. doi: 10. $7150 /$ jca. 25926

Chen, C. M., Wang, J. L., Tsai, Y. T., Jiang, J. H., and Chen, H. L. (2017). "Repurposing metformin for lung cancer management," in A Global Scientific Vision - Prevention, Diagnosis, and Treatment of Lung Cancer, ed. M. Adonis (London: InTech Publishers), 149-163. doi: 10.5772/67160

Chen, Y. Q., and Chen, G. (2015). Combined therapeutic effect and molecular mechanisms of metformin and cisplatin in human lung cancer xenografts in nude mice. J. Cancer Res. Ther. 11, 234-330. doi: 10.4103/0973-1482.151444 
Chuang, M. C., Yang, Y. H., Tsai, Y. H., Hsieh, M. J., Lin, Y. C., Lin, C. K., et al. (2018). Survival benefit associated with metformin use in inoperable non-small cell lung cancer patients with diabetes: a population-based retrospective cohort study. PLoS One 13:e0191129. doi: 10.1371/journal.pone.0191129

Currie, C. J., Poole, C. D., Jenkins-Jones, S., Gale, E. A., Johnson, J. A., and Morgan, C. L. (2012). Mortality after incident cancer in people with and without type 2 diabetes: impact of metformin on survival. Diabetes Care 35, 299-304. doi: $10.2337 / \mathrm{dc} 11-1313$

Emami Riedmaier, A., Fisel, P., Nies, A. T., Schaeffeler, E., and Schwab, M. (2013). Metformin and cancer: from the old medicine cabinet to pharmacological pitfalls and prospects. Trends Pharmacol. Sci. 34, 126-135. doi: 10.1016/j.tips. 2012.11.005

Evans, J. M., Donnelly, L. A., Emslie-Smith, A. M., Alessi, D. R., and Morris, A. D. (2005). Metformin and reduced risk of cancer in diabetic patients. BMJ 330, 1304-1305. doi: 10.1136/bmj.38415.708634.F7

Fatehi Hassanabad, A., and MacQueen, K. T. (2020). Molecular mechanisms underlining the role of metformin as a therapeutic agent in lung cancer. Cell Oncol. 44, 1-18. doi: 10.1007/s13402-020-00570-0

Fonsatti, E., Altomonte, M., Nicotra, M. R., Natali, P. G., and Maio, M. (2003a). Endoglin (CD105): a powerful therapeutic target on tumor-associated angiogenetic blood vessels. Oncogene 22, 6557-6563. doi: 10.1038/sj.onc. 1206813

Fonsatti, E., Sigalotti, L., Arslan, P., Altomonte, M., and Maio, M. (2003b). Emerging role of endoglin (CD105) as a marker of angiogenesis with clinical potential in human malignancies. Curr. Cancer Drug Targets 3, 427-432. doi: 10.2174/1568009033481741

Gong, Y., Wang, C., Jiang, Y., Zhang, S., Feng, S., Fu, Y., et al. (2020). Metformin Inhibits Tumor Metastasis through Suppressing Hsp90 $\alpha$ Secretion in an AMPK $\alpha 1-P K C \gamma$ Dependent Manner. Cells 9:144. doi: 10.3390/cells9010144

Gwinn, D. M., Shackelford, D. B., Egan, D. F., Mihaylova, M. M., Mery, A., Vasquez, D. S., et al. (2008). phosphorylation of raptor mediates a metabolic checkpoint. Mol. Cell 30, 214-226. doi: 10.1016/j.molcel.2008.03.003

Hsu, K. H., Ho, C. C., Hsia, T. C., Tseng, J. S., Su, K. Y., Wu, M. F., et al. (2015). Identification of five driver gene mutations in patients with treatment-naive lung adenocarcinoma in Taiwan. PLoS One 10:e0120852. doi: 10.1371/journal. pone. 0120852

Hung, T. H., Hsu, S. C., Cheng, C. Y., Choo, K. B., Tseng, C. P., Chen, T. C., et al. (2014). Wnt5A regulates ABCB1 expression in multidrug-resistant cancer cells through activation of the non-canonical PKA/ $\beta$-catenin pathway. Oncotarget 5 , 12273-12290. doi: 10.18632/oncotarget.2631

Iliopoulos, D., Hirsch, H. A., and Struhl, K. (2011). Metformin decreases the dose of chemotherapy for prolonging tumor remission in mouse xenografts involving multiple cancer cell types. Cancer Res. 71, 3196-3201. doi: 10.1158/0008-5472. CAN-10-3471

Joe, S. G., Yoon, Y. H., Choi, J. A., and Koh, J. Y. (2015). Anti-angiogenic effect of metformin in mouse oxygen-induced retinopathy is mediated by reducing levels of the vascular endothelial growth factor receptor Flk-1. PLoS One 10:e0119708. doi: 10.1371/journal.pone.0119708

Kang, J., Jeong, S. M., Shin, D. W., Cho, M., Cho, J. H., and Kim, J. (2021). The associations of aspirin, statins, and metformin with lung cancer risk and related mortality: a time-dependent analysis of population-based nationally representative data. J. Thorac. Oncol. 16, 76-88. doi: 10.1016/j.jtho.2020.08.021

Kato, K., Gong, J., Iwama, H., Kitanaka, A., Tani, J., Miyoshi, H., et al. (2012). The antidiabetic drug metformin inhibits gastric cancer cell proliferation in vitro and in vivo. Mol. Cancer Ther. 11, 549-560. doi: 10.1158/15 35-7163.MCT-11-0594

Körbler, T., Grsković, M., Dominis, M., and Antica, M. A. (2003). simple method for RNA isolation from formalin-fixed and paraffin-embedded lymphatic tissues. Exp. Mol. Pathol. 74, 336-340. doi: 10.1016/S0014-4800(03)00024-8

Lai, C. W., Chen, H. L., Yen, C. C., Wang, J. L., Yang, S. H., and Chen, C. M. (2016). Using dual fluorescence reporting genes to establish an in vivo imaging model of orthotopic lung adenocarcinoma in mice. Mol. Imaging Biol. 18, 849-859. doi: 10.1007/s11307-016-0967-4

Lai, S. W., Liao, K. F., Chen, P. C., Tsai, P. Y., Hsieh, D. P., and Chen, C. C. (2012). Antidiabetes drugs correlate with decreased risk of lung cancer: a populationbased observation in Taiwan. Clin. Lung Cancer 13, 143-148. doi: 10.1016/j.cllc. 2011.10.002
Lan, Y. W., Choo, K. B., Chen, C. M., Hung, T. H., Chen, Y. B., Hsieh, C. H., et al. (2015). Hypoxia-preconditioned mesenchymal stem cells attenuate bleomycininduced pulmonary fibrosis. Stem Cell Res. Ther. 6:97. doi: 10.1186/s13287-0150081-6

Lan, Y. W., Theng, S. M., Huang, T. T., Choo, K. B., Chen, C. M., Kuo, H. P., et al. (2017). Oncostatin M-preconditioned mesenchymal stem cells alleviate bleomycin-induced pulmonary fibrosis through paracrine effects of the hepatocyte growth factor. Stem Cells Transl. Med. 6, 1006-1017. doi: 10.5966/ sctm.2016-0054

Lan, Y. W., Yang, J. C., Yen, C. C., Huang, T. T., Chen, Y. C., Chen, H. L., et al. (2019). Predifferentiated amniotic fluid mesenchymal stem cells enhance lung alveolar epithelium regeneration and reverse elastase-induced pulmonary emphysema. Stem Cell Res. Ther. 10, 163. doi: 10.1186/s13287-019-1282-1

Levy, A., and Doyen, J. (2018). Metformin for non-small cell lung cancer patients: Opportunities and pitfalls. Crit. Rev. Oncol. Hematol. 125, 41-47. doi: 10.1016/ j.critrevonc.2018.03.001

Lin, C. C., Yeh, H. H., Huang, W. L., Yan, J. J., Lai, W. W., Su, W. P., et al. (2013). Metformin enhances cisplatin cytotoxicity by suppressing signal transducer and activator of transcription-3 activity independently of the liver kinase B1-AMPactivated protein kinase pathway. Am. J. Respir. Cell Mol. Biol. 49, 241-250. doi: 10.1165/rcmb.2012-0244OC

Lin, J. J., Gallagher, E. J., Sigel, K., Mhango, G., Galsky, M. D., Smith, C. B., et al. (2015). Survival of patients with stage IV lung cancer with diabetes treated with metformin. Am. J. Respir. Crit. Care Med. 191, 448-454. doi: 10.1164/rccm. 201407-1395OC

Luo, Z., Chen, W., Wu, W., Luo, W., Zhu, T., Guo, G., et al. (2019). Metformin promotes survivin degradation through AMPK/PKA/GSK-3beta-axis in nonsmall cell lung cancer. J. Cell Biochem. 120, 11890-11899. doi: 10.1002/jcb. 28470

Marrone, K. A., Zhou, X., Forde, P. M., Purtell, M., Brahmer, J. R., Hann, C. L., et al. (2018). A randomized phase II study of metformin plus paclitaxel/carboplatin/bevacizumab in patients with chemotherapy-naive advanced or metastatic nonsquamous non-small cell lung cancer. Oncologist 23, 859-865. doi: 10.1634/theoncologist.2017-0465

Mok, T. S., Wu, Y. L., Ahn, M. J., Garassino, M. C., Kim, H. R., Ramalingam, S. S., et al. (2017). Osimertinib or platinum-pemetrexed in EGFR T790M-positive lung cancer. N. Engl. J. Med. 376, 629-640. doi: 10.1056/NEJMoa1612674

Parikh, A. B., Kozuch, P., Rohs, N., Becker, D. J., and Levy, B. P. (2017). Metformin as a repurposed therapy in advanced non-small cell lung cancer (NSCLC): results of a phase II trial. Invest. New Drugs 35, 813-819. doi: 10.1007/s10637017-0511-7

Parikh, A. B., Marrone, K. A., Becker, D. J., Brahmer, J. R., Ettinger, D. S., and Levy, B. P. A. (2019). pooled analysis of two phase II trials evaluating metformin plus platinum-based chemotherapy in advanced non-small cell lung cancer. Cancer Treat. Res. Commun. 20:100150. doi: 10.1016/j.ctarc.2019.100150

Pawalowska, M., and Markowska, A. (2012). The influence of metformin in the etiology of selected cancers. Contemp. Oncol. 16, 223-229. doi: 10.5114/wo. 2012.29289

Peng, M., Darko, K. O., Tao, T., Huang, Y., Su, Q., He, C., et al. (2017). Combination of metformin with chemotherapeutic drugs via different molecular mechanisms. Cancer Treat. Rev. 54, 24-33. doi: 10.1016/j.ctrv.2017. 01.005

Rattan, R., Graham, R. P., Maguire, J. L., Giri, S., and Shridhar, V. (2011). Metformin suppresses ovarian cancer growth and metastasis with enhancement of cisplatin cytotoxicity in vivo. Neoplasia 13, 483-491. doi: 10.1593/neo.11148

Reck, M., Rodriguez-Abreu, D., Robinson, A. G., Hui, R., Csoszi, T., Fulop, A., et al. (2016). Pembrolizumab versus chemotherapy for PD-L1-positive non-smallcell lung cancer. N. Engl. J. Med. 375, 1823-1833. doi: 10.1056/NEJMoa1606774

Reck, M., Rodriguez-Abreu, D., Robinson, A. G., Hui, R., Csoszi, T., Fulop, A., et al. (2019). Updated analysis of KEYNOTE-024: pembrolizumab versus platinum-based chemotherapy for advanced non-small-cell lung cancer with PD-L1 tumor proportion score of 50\% or greater. J. Clin. Oncol. 37, 537-546. doi: 10.1200/JCO.18.00149

Satouchi, M., Nosaki, K., Takahashi, T., Nakagawa, K., Aoe, K., Kurata, T., et al. (2020). First-line pembrolizumab vs chemotherapy in metastatic non-smallcell lung cancer: KEYNOTE-024 Japan subset. Cancer Sci. 111, 4480-4489. doi: $10.1111 /$ cas. 14647 
Saxena, A., Becker, D., Preeshagul, I., Lee, K., Katz, E., and Levy, B. (2015). Therapeutic effects of repurposed therapies in non-small cell lung cancer: what is old is new again. Oncologist 20, 934-945. doi: 10.1634/theoncologist.20150064

Scagliotti, G. V., Parikh, P., von Pawel, J., Biesma, B., Vansteenkiste, J., Manegold, C., et al. (2008). Phase III study comparing cisplatin plus gemcitabine with cisplatin plus pemetrexed in chemotherapy-naive patients with advanced-stage non-small-cell lung cancer. J. Clin. Oncol. 26, 3543-3551. doi: 10.1200/JCO. 2007.15.0375

Shaw, R. J., Lamia, K. A., Vasquez, D., Koo, S. H., Bardeesy, N., Depinho, R. A., et al. (2005). The kinase LKB1 mediates glucose homeostasis in liver and therapeutic effects of metformin. Science 310, 1642-1646. doi: 10.11 26/science.1120781

Siegel, R. L., Miller, K. D., and Jemal, A. (2017). Cancer Statistics, 2017. CA Cancer J. Clin. 67, 7-30. doi: 10.3322/caac.21387

Sinnett-Smith, J., Kisfalvi, K., Kui, R., and Rozengurt, E. (2013). Metformin inhibition of mTORC1 activation, DNA synthesis and proliferation in pancreatic cancer cells: dependence on glucose concentration and role of AMPK. Biochem. Biophys. Res. Commun. 430, 352-357. doi: 10.1016/j.bbrc. 2012.11.010

Soria, J. C., Tan, D. S. W., Chiari, R., Wu, Y. L., Paz-Ares, L., Wolf, J., et al. (2017). First-line ceritinib versus platinum-based chemotherapy in advanced ALK-rearranged non-small-cell lung cancer (ASCEND-4): a randomised, open-label, phase 3 study. Lancet 389, 917-929. doi: 10.10 16/S0140-6736(17)30123-X

Steiner, P., Joynes, C., Bassi, R., Wang, S., Tonra, J. R., Hadari, Y. R., et al. (2007). Tumor growth inhibition with cetuximab and chemotherapy in non-small cell lung cancer xenografts expressing wild-type and mutated epidermal growth factor receptor. Clin. Cancer Res. 13, 1540-1551. doi: 10.11 58/1078-0432.CCR-06-1887

Tosetti, F., Ferrari, N., De Flora, S., and Albini, A. (2002). Angioprevention: angiogenesis is a common and key target for cancer chemopreventive agents. FASEB J. 16, 2-14. doi: 10.1096/fj.01-0300rev

Tseng, C. H., Tsuang, B. J., Chiang, C. J., Ku, K. C., Tseng, J. S., Yang, T. Y., et al. (2019). The relationship between air pollution and lung cancer in nonsmokers in Taiwan. J. Thorac. Oncol. 14, 784-792. doi: 10.1016/j.jtho.2018. 12.033

Tseng, S. C., Huang, Y. C., Chen, H. J., Chiu, H. C., Huang, Y. J., Wo, T. Y., et al. (2013). Metformin-mediated downregulation of p38 mitogenactivated protein kinase-dependent excision repair cross-complementing 1 decreases DNA repair capacity and sensitizes human lung cancer cells to paclitaxel. Biochem. Pharmacol. 85, 583-594. doi: 10.1016/j.bcp.2012. 12.001

Tung, Y. T., Huang, P. W., Chou, Y. C., Lai, C. W., Wang, H. P., Ho, H. C., et al. (2015). Lung tumorigenesis induced by human vascular endothelial growth factor (hVEGF)-A165 overexpression in transgenic mice and amelioration of tumor formation by miR-16. Oncotarget 6, 10222-10238. doi: 10.18632/ oncotarget. 3390

Vernieri, C., Signorelli, D., Galli, G., Ganzinelli, M., Moro, M., Fabbri, A., et al. (2019). Exploiting fasting-mimicking diet and metformin to improve the efficacy of platinum-pemetrexed chemotherapy in advanced LKB1-inactivated lung adenocarcinoma: the FAME trial. Clin. Lung Cancer 20, e413-e417. doi: 10.1016/j.cllc.2018.12.011

Wang, G., Lin, F., Wan, Q., Wu, J., and Luo, M. (2020). Mechanisms of action of metformin and its regulatory effect on microRNAs related to angiogenesis. Pharmacol. Res. 164:105390. doi: 10.1016/j.phrs.2020.105390

Wang, K., Li, Q., Shi, R., Yang, D., Zou, W., and Mu, K. (2018). Increased CD105 expression is associated with disease progression in phyllodes tumors - a report of a borderline phyllodes tumor with lung metastases and a study of 54 phyllodes tumors. Ann. Diagn. Pathol. 32, 4-9. doi: 10.1016/j.anndiagpath. 2017.04.002

Weis, S. M., and Cheresh, D. A. (2011). Tumor angiogenesis: molecular pathways and therapeutic targets. Nat. Med. 17, 1359-1370. doi: 10.1038/nm.2537

Zakikhani, M., Dowling, R., Fantus, I. G., Sonenberg, N., and Pollak, M. (2006). Metformin is an AMP kinase-dependent growth inhibitor for breast cancer cells. Cancer Res. 66, 10269-10273. doi: 10.1158/0008-5472.CAN-06- 1500

Zhang, Y., Feng, X., Li, T., Yi, E., and Li, Y. (2017). Metformin synergistic pemetrexed suppresses non-small-cell lung cancer cell proliferation and invasion in vitro. Cancer Med. 6, 1965-1975. doi: 10.10 02/cam4.1133

Conflict of Interest: The authors declare that the research was conducted in the absence of any commercial or financial relationships that could be construed as a potential conflict of interest.

Copyright (c) 2021 Wang, Lan, Tsai, Chen, Staniczek, Tsou, Yen and Chen. This is an open-access article distributed under the terms of the Creative Commons Attribution License (CC BY). The use, distribution or reproduction in other forums is permitted, provided the original author(s) and the copyright owner(s) are credited and that the original publication in this journal is cited, in accordance with accepted academic practice. No use, distribution or reproduction is permitted which does not comply with these terms. 